Results from a randomized, double-blind, placebo-controlled, monotherapy trial of IMO-8400 demonstrate clinical proofof-concept for Toll-like receptor 7, 8 and 9 antagonism in psoriasis

D.M.W. Balak', M.B.A. van Doorn', R. Rissmann², T. Sullivan ${ }^{3}$, J. Burggraaf' ${ }^{2}$, R.D. Arbeit ${ }^{3}$

${ }^{1}$ Department of Dermatology, Erasmus MC, Rotterdam, the Netherlands; ${ }^{2}$ Centre for Human Drug Research, Leiden, the Netherlands; ${ }^{3}$ dera Pharmaceuticals, Cambridge, Massachusetts, USA. 


\section{Study background}

- Toll-like receptors (TLRs) are a key component of the innate immune system

- In various immune-mediated inflammatory diseases (IMIDs), including psoriasis, TLRs are engaged by self nucleic acids, leading to induction of pro-inflammatory cytokines and disease propagation

- TLRs represent potentially attractive targets for the treatment of IMIDs due to their role in regulating the inflammatory response upstream of immune cell activation and cytokine induction

- IMO-8400 is a novel, oligonucleotide antagonist of endosomal TLRs 7, 8 and 9

- In an IL-23-induced skin inflammation mouse model, IMO-8400 treatment resulted in modulation of more than 2,300 disease-associated genes, strongly decreased IL-17A expression (>12-fold reduction), and normalized IL-17 induced genes such as beta-defensin and CXCL1 ${ }^{1}$

- In a Phase 1 healthy volunteer trial, IMO-8400 was generally well tolerated

- In addition, a previously completed Phase 2a trial of a separate TLR 7 and 9 antagonist candidate showed improvements in PASI score in subjects with moderate to severe plaque psoriasis. In biopsies from a subset of subjects, there was a significant improvement in the expression profile of MAD-3 and IL-17 genes ${ }^{2}$

- A Phase 2 clinical trial of IMO-8400 was designed to evaluate the safety, tolerability, and clinical activity of IMO-8400 in patients with moderate to severe plaque psoriasis

- This randomized, single-center, double-blind, placebo-controlled, monotherapy, dose-ranging trial evaluated four IMO-8400 doses of $0.075,0.15,0.30$ and $0.60 \mathrm{mg} / \mathrm{kg} /$ week 


\section{Endosomal TLRs play a critical role in the pathogenesis of psoriasis}

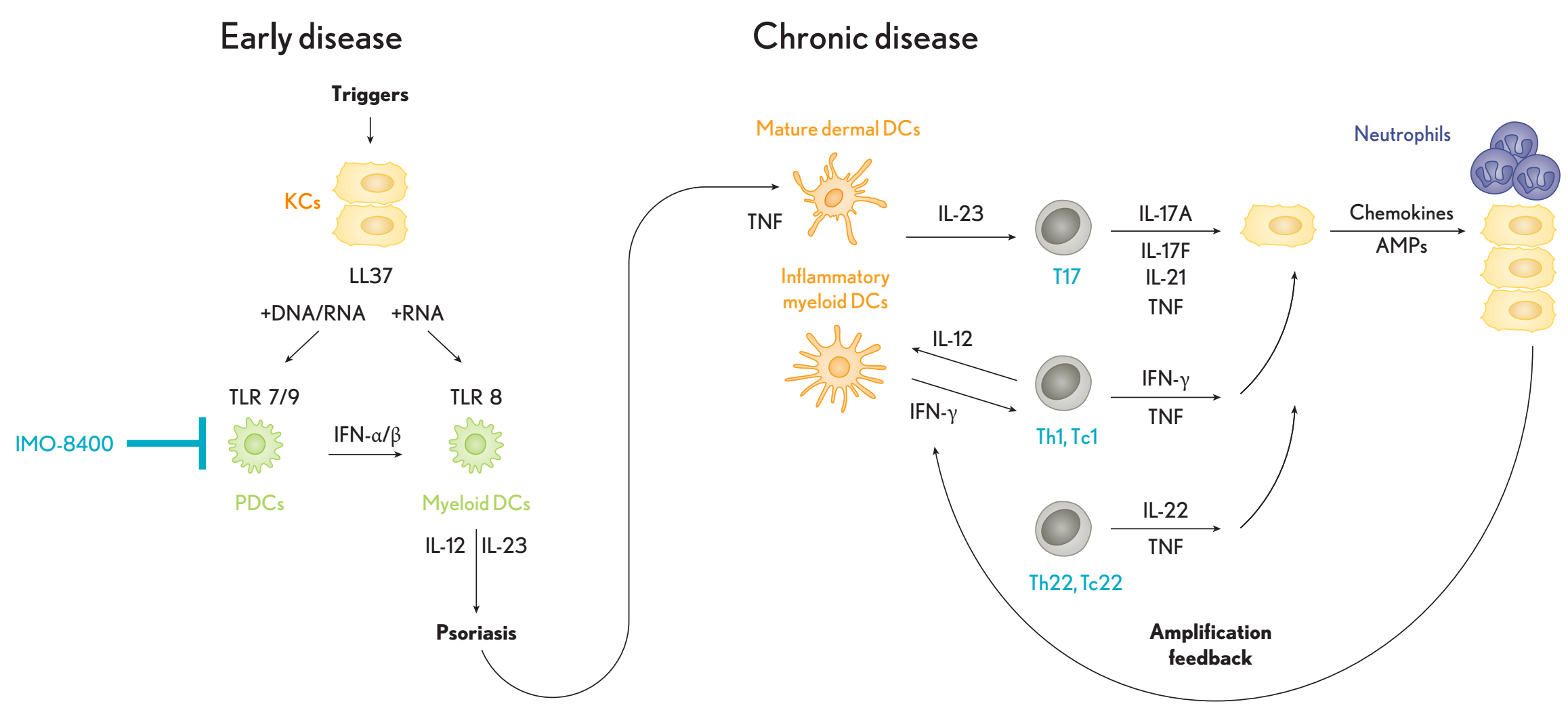

Graphic adapted from: Lowes, et al. Immunology of Psoriasis. Annu Rev Immunol. 2014. 32:227-55.

- Cells damaged by injury or infection release self DNA, self RNA and other molecules to form Damage Associated Molecular Patterns (DAMPs)

- DAMPs stimulate TLR signaling in dendritic cells and keratinocytes leading to induction of pro-inflammatory cytokines and T-cell activation

- Inflammation causes activation and proliferation of keratinocytes, leading to formation of psoriasis plaques 
Design of a Phase 2 randomized, double-blind, placebo-controlled, proof-ofconcept trial of IMO-8400 in moderate to severe plaque psoriasis

\section{Adult patients with moderate to severe psoriasis}

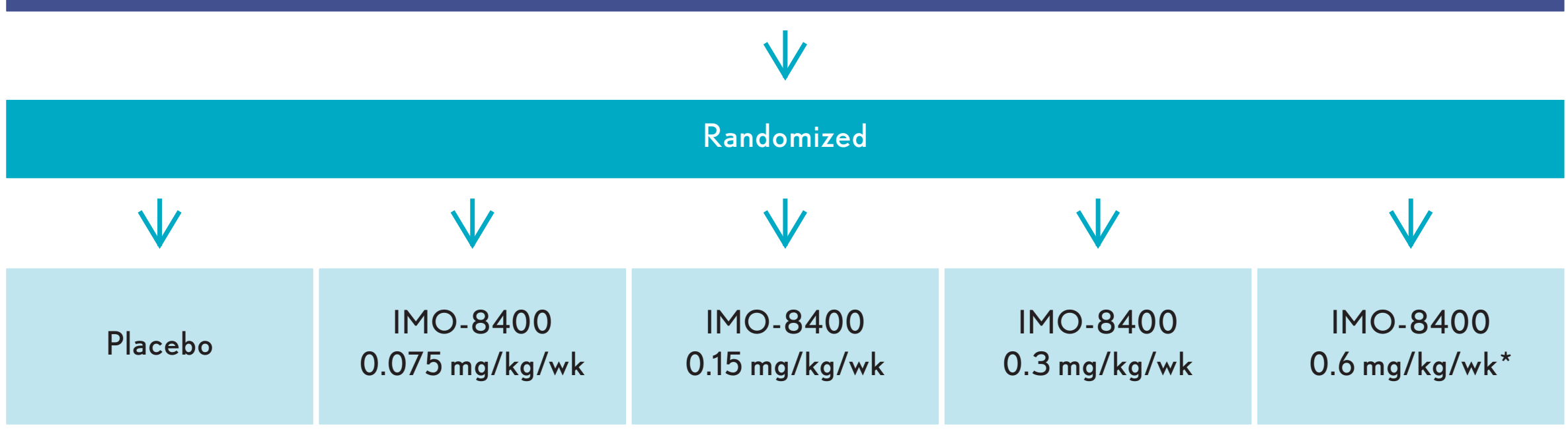

\section{Treated once weekly by s.c. injection for 12 weeks, then follow-up for 6 weeks}

Major entry criteria:

- Aged $\geq 18$ years

- Psoriasis area and severity index (PASI) score $\geq 12$

- Body surface area $\geq 10 \%$

*Part B expansion to $0.6 \mathrm{mg} / \mathrm{kg} / \mathrm{wk}$.
Primary outcome measure:

- Safety and tolerability of four IMO-8400 doses

Secondary outcome measures included:

- PASI score

- Individual characteristics of psoriasis severity 


\section{Minimum discontinuation intervals required for prior treatments for psoriasis}

\begin{tabular}{lll} 
Treatment class & Specific examples & Discontinuation interval* \\
\hline Topical & retinoids, corticosteroids, vitamin D analogs & 2 weeks \\
Phototherapy & any & 4 weeks \\
Systemic retinoids & acitretin & 4 weeks \\
Systemic non-biologic & methotrexate, cyclosporine, oral corticosteroids, & 4 weeks \\
immune modulators & fumaric acid esters & 8 weeks \\
& antimalarials, (e.g., hydroxychloroquine) & 4 weeks \\
Biologic immune modulators & etanercept & 26 weeks \\
& ustekinumab & 8 weeks \\
\hline
\end{tabular}

*Minimum interval from the last dose of treatment to the first dose of study treatment (i.e., Day 1 ).

\section{Subjects enrolled and disposition}

\begin{tabular}{ccccccc} 
& \multicolumn{4}{c}{ IMO-8400 (mg/kg) } & Placebo & Overall \\
\cline { 2 - 5 } & $\mathbf{0 . 0 7 5}$ & $\mathbf{0 . 1 5}$ & $\mathbf{0 . 3 0}$ & $\mathbf{0 . 6 0}$ & & 46 \\
Subjects treated & 9 & 9 & 8 & 9 & 11 & 46 \\
Prematurely discontinued treatment & $2(22.2 \%)$ & $2(22.2 \%)$ & $2(25.0 \%)$ & 0 & $2(18.2 \%)$ & $8(17.4 \%)$ \\
AE not related to treatment & $1(11.1 \%)$ & 0 & 0 & 0 & $1(9.1 \%)$ & $2(4.3 \%)$ \\
Withdrawal of consent & $1(11.1 \%)$ & $2(22.2 \%)$ & 0 & 0 & 0 & $3(6.5 \%)$ \\
Lack of efficacy & 0 & 0 & $2(25.0 \%)^{*}$ & 0 & $1(9.1 \%)$ & $3(6.5 \%)$ \\
\hline
\end{tabular}

*One patient discontinued treatment after experiencing a severe treatment-emergent adverse event that was unlikely related to study treatment; however, termination was listed as due to lack of efficacy.

- 46 subjects enrolled and treated

- $8(17 \%)$ discontinued early 


\section{Baseline characteristics were generally balanced across treatment groups}

\begin{tabular}{|c|c|c|c|c|c|}
\hline \multirow[b]{2}{*}{ PARAMETER } & \multicolumn{4}{|c|}{ IMO-8400 dose } & \multirow[b]{2}{*}{$\begin{array}{c}\text { Placebo } \\
(n=11)\end{array}$} \\
\hline & $\begin{array}{c}0.075 \mathrm{mg} / \mathrm{kg} \\
(\mathrm{n}=9)\end{array}$ & $\begin{array}{c}0.15 \mathrm{mg} / \mathrm{kg} \\
(\mathrm{n}=9)\end{array}$ & $\begin{array}{c}0.30 \mathrm{mg} / \mathrm{kg} \\
(\mathrm{n}=8)\end{array}$ & $\begin{array}{c}0.60 \mathrm{mg} / \mathrm{kg} \\
(\mathrm{n}=9)\end{array}$ & \\
\hline \multicolumn{6}{|l|}{ Age, years } \\
\hline Mean (SD) & $48.8(15.1)$ & $35.0(16.0)$ & $42.3(17.2)$ & $47.9(13.3)$ & 47.2 (13.4) \\
\hline \multicolumn{6}{|l|}{ Gender, n (\%) } \\
\hline Male & $5(55.6 \%)$ & $6(66.7 \%)$ & $6(75.0 \%)$ & $8(88.9 \%)$ & $9(82.8 \%)$ \\
\hline Female & $4(44.4 \%)$ & $3(33.3 \%)$ & $2(25.0 \%)$ & $1(11.1 \%)$ & $2(18.2 \%)$ \\
\hline \multicolumn{6}{|l|}{$\mathrm{BMI}, \mathrm{kg} / \mathrm{m}^{2}$} \\
\hline Mean (SD) & $25.8(4.5)$ & $24.1(4.9)$ & $27.1(1.3)$ & $28.1(5.8)$ & $29.8(3.9)$ \\
\hline \multicolumn{6}{|l|}{ Race, n (\%) } \\
\hline White & $5(56 \%)$ & $8(89 \%)$ & $6(75 \%)$ & $9(100 \%)$ & $8(73 \%)$ \\
\hline Asian & 0 & 0 & $2(25 \%)$ & 0 & $2(18 \%)$ \\
\hline Mixed & $2(22 \%)$ & 0 & 0 & 0 & $1(9 \%)$ \\
\hline Other & $2(22 \%)$ & $1(11 \%)$ & 0 & 0 & 0 \\
\hline \multicolumn{6}{|c|}{ Disease characteristics, mean (SD) } \\
\hline PASI & $14.1(2.6)$ & $14.1(2.0)$ & $14.8(2.7)$ & $14.2(2.0)$ & $14.1(2.5)$ \\
\hline
\end{tabular}

$\mathrm{BMI}=$ body mass index; $\mathrm{PASI}=$ psoriasis area and severity index . 
Summary of adverse events assessed as related to study drug by preferred term ( $\geq 1$ event)

\begin{tabular}{|c|c|c|}
\hline \multirow{2}{*}{ Preferred Term ( $\geq 1$ event) } & All IM0-8400-related & All placebo-related \\
\hline & $n=35$ & $n=11$ \\
\hline Any event & 24 (69\%) & $6(54 \%)$ \\
\hline Diarrhea & $6(17 \%)$ & - \\
\hline Fatigue & $6(17 \%)$ & - \\
\hline Influenza-like illness & $6(17 \%)$ & $1(9 \%)$ \\
\hline Nausea & $3(9 \%)$ & - \\
\hline Abdominal discomfort & $2(6 \%)$ & - \\
\hline Vomiting & $2(6 \%)$ & - \\
\hline Somnolence & $2(6 \%)$ & - \\
\hline Polyuria & $2(6 \%)$ & - \\
\hline Muscle spasms & - & $2(18 \%)$ \\
\hline
\end{tabular}

Summary of injection site reactions (ISRs)

\begin{tabular}{|c|c|c|c|c|c|}
\hline \multirow[b]{2}{*}{ ISR type } & \multicolumn{4}{|c|}{ IMO-8400 dose } & \multirow[b]{2}{*}{$\begin{array}{l}\text { Placebo } \\
(n=11)\end{array}$} \\
\hline & $\begin{array}{c}0.075 \mathrm{mg} / \mathrm{kg} \\
(\mathrm{n}=9)\end{array}$ & $\begin{array}{c}0.15 \mathrm{mg} / \mathrm{kg} \\
(\mathrm{n}=9)\end{array}$ & $\begin{array}{c}0.30 \mathrm{mg} / \mathrm{kg} \\
(\mathrm{n}=8)\end{array}$ & $\begin{array}{c}0.60 \mathrm{mg} / \mathrm{kg} \\
(\mathrm{n}=9)\end{array}$ & \\
\hline Any ISR & 4 (44\%) & 3 (33\%) & 7 (87\%) & 9 (100\%) & $1(9 \%)$ \\
\hline Erythema & $4(44 \%)$ & $2(22 \%)$ & $6(75 \%)$ & 9 (100\%) & $1(9 \%)$ \\
\hline Induration & - & 1 (11\%) & $4(50 \%)$ & 8 (89\%) & $1(9 \%)$ \\
\hline Pruritus & $2(22 \%)$ & - & $5(62 \%)$ & $5(56 \%)$ & - \\
\hline Tenderness & - & 1 (11\%) & $4(50 \%)$ & $4(44 \%)$ & - \\
\hline Pain & - & - & $2(25 \%)$ & 1 (11\%) & - \\
\hline
\end{tabular}




\section{Safety results}

\section{Summary}

- There were no SAEs, no treatment-related severe AEs, and no discontinuations due to treatment-related AEs

- The frequency of diarrhea, fatigue and influenza-like illness was numerically higher among IMO-8400-treated subjects

- No abnormalities of laboratory results of hematology, chemistry, coagulation and urinalysis were attributed to study drug

- Analysis of the primary data by numerical values and by Common Terminology Criteria grading showed no differences between the subjects treated with IMO-8400 or placebo

\section{Injection-site reactions}

- There was a dose-related increase in the frequency of ISRs in IMO-8400-treated subjects

- All ISRs were assessed as mild or moderate

- No blistering, ulceration, or necrosis was observed in any subject

- Mild Koebner reactions involving the development of small $(2-4 \mathrm{~cm})$ plaques of psoriasis at the site of injection were observed in $2(25 \%)$ subjects in the $0.3 \mathrm{mg} / \mathrm{kg}$ group and $4(44 \%)$ subjects in the $0.60 \mathrm{mg} / \mathrm{kg}$ group 


\section{Psoriasis Area and Severity Index (PASI) responder analysis}

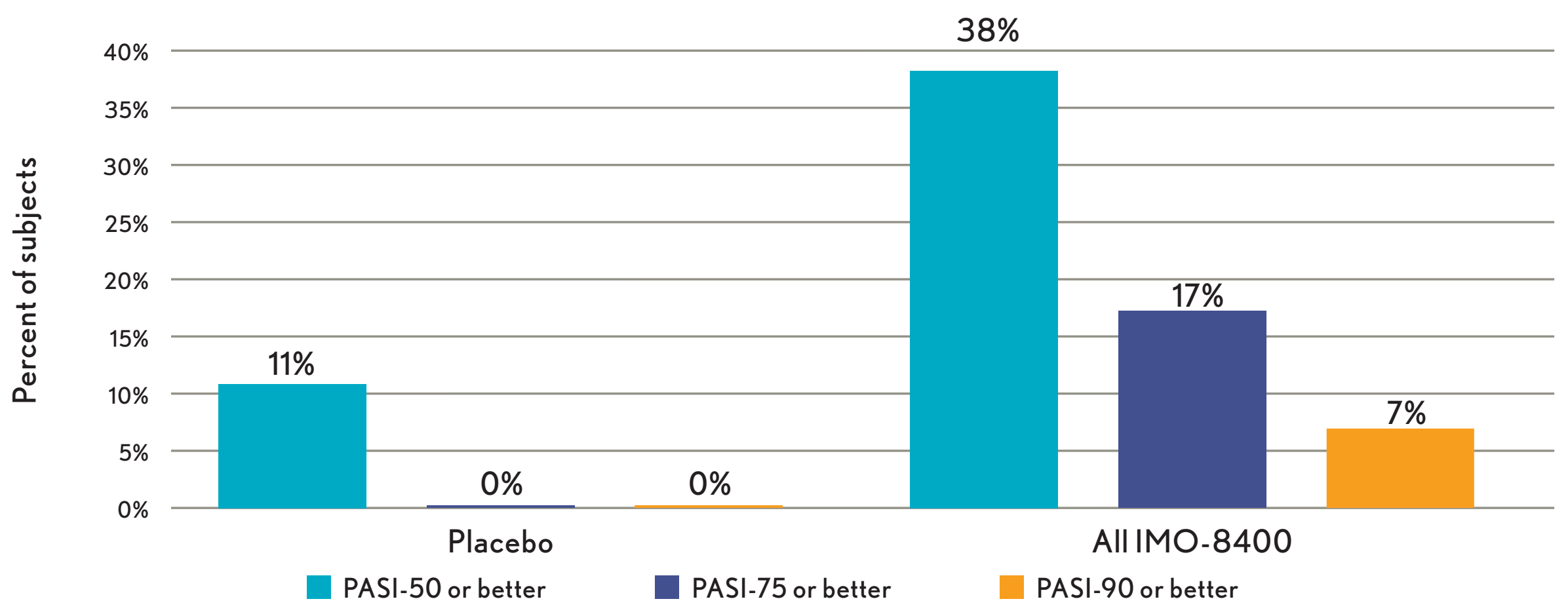

\begin{tabular}{lcccccc} 
& & \multicolumn{3}{c}{ IM0-8400 (mg/kg) } \\
\cline { 3 - 7 } RESPONSE & Placebo & All IMO-8400 & $\mathbf{0 . 0 7 5}$ & $\mathbf{0 . 1 5}$ & $\mathbf{0 . 3 0}$ & $\mathbf{0 . 6 0}$ \\
PASI-50 or better & $(\mathbf{N}=9)$ & $(\mathbf{N}=29)$ & $(\mathbf{N}=7)$ & $(\mathbf{N}=7)$ & $(\mathbf{N}=6)$ & $(\mathbf{N}=9)$ \\
PASI-75 or better & $1(11 \%)$ & $11(38 \%)$ & $3(43 \%)$ & $3(43 \%)$ & $3(50 \%)$ & $2(22 \%)$ \\
PASI-90 or better & 0 & $5(17 \%)$ & $2(29 \%)$ & $2(29 \%)$ & 0 & $1(11 \%)$ \\
\hline
\end{tabular}

There were no statistically significant differences in the percent change in PASI score between treatment groups.

PASI-50 = 50\% reduction in PASI score; PASI-75 = 75\% reduction in PASI score; PASI-90 = 90\% reduction in PASI score. 


\section{Example of psoriasis plaque improvement in an IMO-8400. treated subject}

\section{Pre-Treatment}

4 weeks after 12 weeks $\mathrm{Tx}$

Baseline PASI: 16.6

End-of-study response: $-82.5 \%$
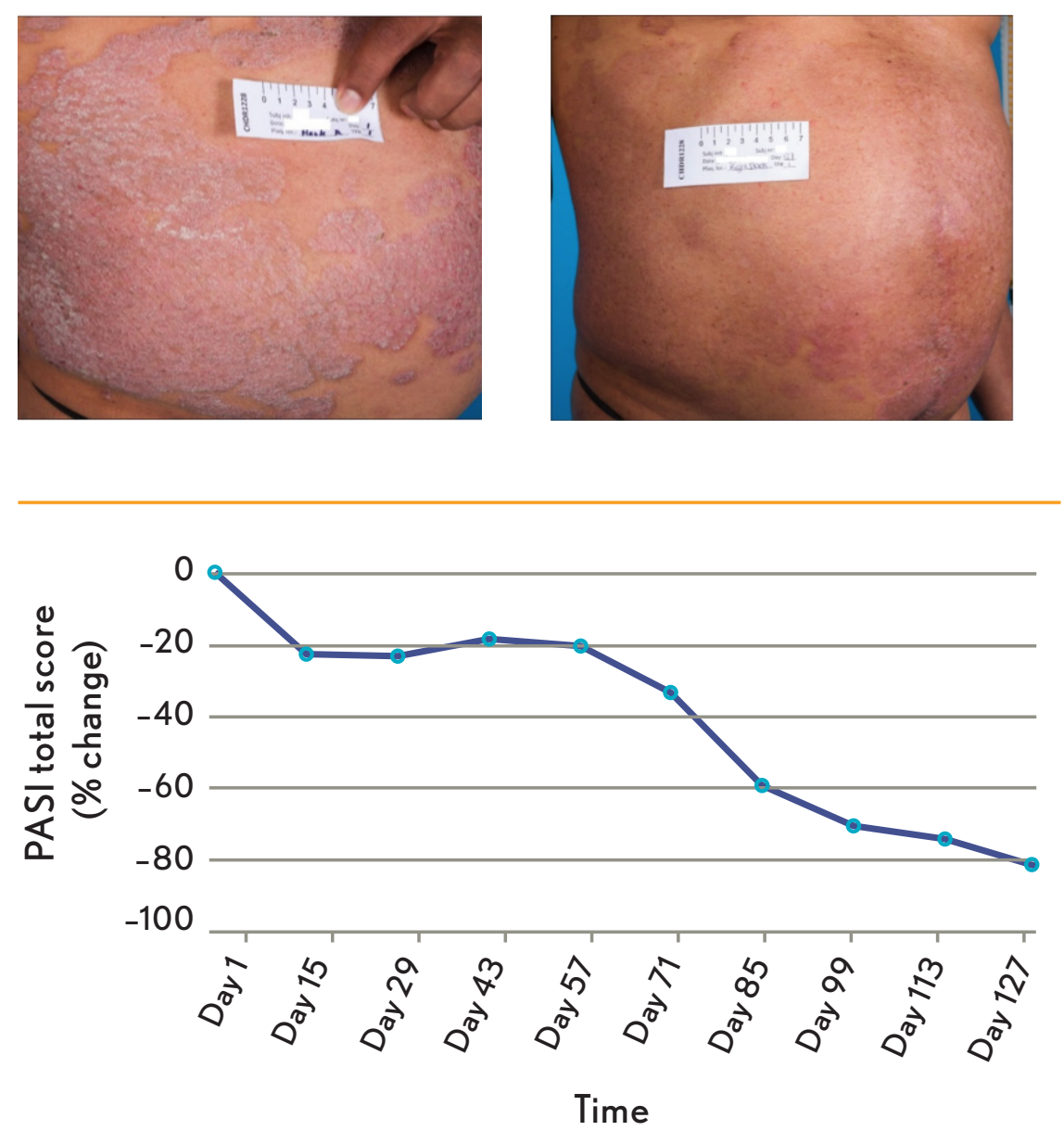

Note: Subject was in $0.075 \mathrm{mg} / \mathrm{kg}$ treatment group.
Correlation of percent change in PASI and human beta-defensin 2, a marker of epithelial cell activation

- Plasma samples were collected at multiple time points during the study including during pretreatment, treatment and follow-up periods to assess cytokine levels

- Human beta-defensin 2 (hBD2) is an antimicrobial peptide produced by keratinocytes following stimulation due to contact with microorganisms or pro-inflammatory cytokines

- There was a significant correlation between percent change in PASI score and hBD2 $(r=0.57, p<0.0001)$
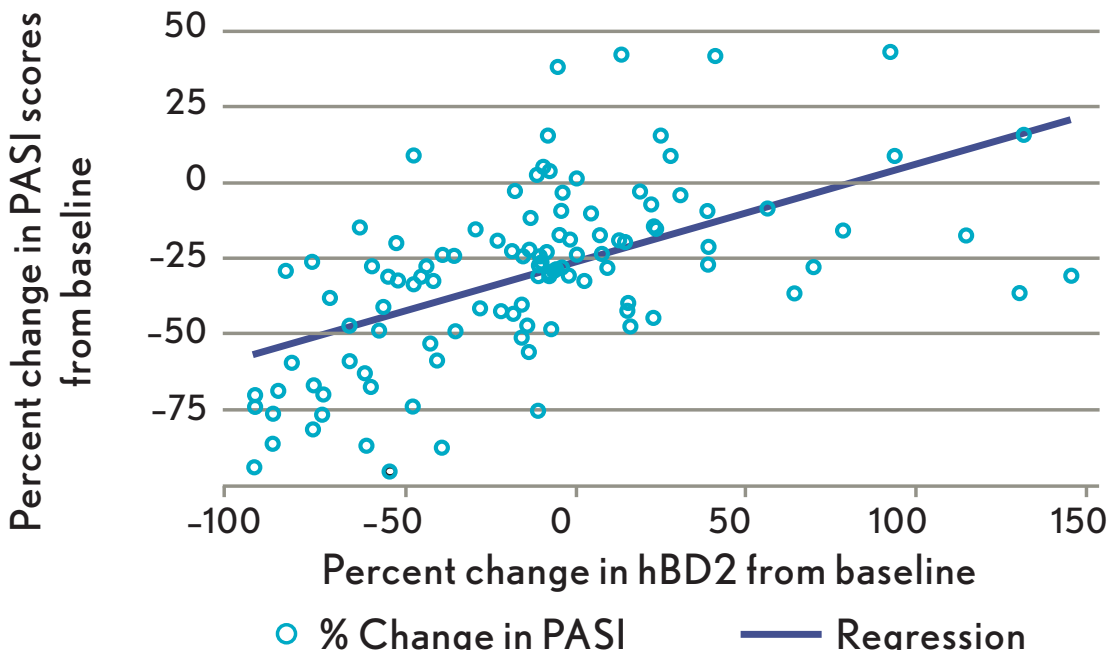


\section{Clinical activity results}

\section{Summary}

- Improvements in PASI scores of 50\% to 92\% were observed in 11 (38\%) of IMO-8400-treated patients; only 1 (11\%) placebo-treated patient had an improvement in this range

- Evidence of a persistent treatment effect was observed in 8 (28\%) IMO-8400-treated patients, who had PASI-50 or better at the follow-up visit 6 weeks after the last dose of study drug. A similar effect was not observed in the placebo group

- All doses showed evidence of clinical activity and a clear dose-response relationship was not observed

\section{Conclusions}

- The trial met its primary objective of demonstrating the safety and tolerability of IMO-8400 treatment for up to 12 weeks in patients with moderate to severe plaque psoriasis

- IMO-8400-treated patients were more likely to demonstrate an improvement in PASI score compared to placebo-treated patients

- 11 (38\%) IMO-8400-treated subjects achieved PASI-50 or better versus 1 (11\%) placebo-treated subject

- These findings demonstrate clinical proof of concept for TLR 7, 8 and 9 antagonism with IMO-8400 and support its continued development as a potential treatment for IMIDs in which TLRs are implicated

- Planning is now underway to initiate clinical development of IMO-8400 in patients with dermatomyositis, a rare and severe IMID with skin and muscle manifestations 


\section{Acknowledgements and disclosures}

- This study was sponsored by Idera Pharmaceuticals

- D.M.W. Balak and M.B.A. van Doorn received research funding from Idera Pharmaceuticals to support the conduct of this study

- R. Rissman and J. Burggraaf are employed by the Centre for Human Drug Research, which received payment from Idera Pharmaceuticals to assist with the conduct of this study

- T. Sullivan is an employee of Idera Pharmaceuticals and may own Idera Pharmaceuticals stock or stock options

- R.D. Arbeit is a consultant to and former employee of Idera Pharmaceuticals and may own Idera

Pharmaceuticals stock or stock options 